\title{
LA COMUNICACIÓN PUBLICITARIA CON INFLUENCERS
}

\author{
Castelló Martínez, Araceli ${ }^{1}$ \\ Universidad de Alicante \\ araceli.castello@ua.es
}

del Pino Romero, Cristina²

Universidad Carlos III de Madrid

cpino@hum.uc3m.es

Material original autorizado para su primera publicación en la revista académica REDMARKA. Revista Digital de Marketing Aplicado.

https://doi.org/10.17979/redma.2015.01.014.4880

Recibido: 4 Mayo 2015

Aceptado 10 Junio 2015

\section{Resumen}

La figura del prescriptor ha sido uno de los recursos más utilizados en publicidad a lo largo de toda su historia. Con la popularización de las redes sociales, el poder

${ }^{1}$ Doctora en Comunicación por la Universidad Cardenal Herrera-CEU, Máster en Comunicación Integral por la Universidad Complutense de Madrid, Máster Ejecutivo en Community Management por la Universidad de Alicante y Licenciada en Publicidad y RR.PP. por la Universidad de Alicante, con premio extraordinario de Licenciatura y segundo premio nacional. Imparte docencia en los estudios de Publicidad y RR.PP. en la Universidad de Alicante. Ha sido también profesora en la Licenciatura en Publicidad y RR.PP. de la Universidad CEU-Cardenal Herrera y colabora como profesora en postgrados de diversas Universidades.

${ }^{2}$ Doctora en Comunicación por la Universidad de Málaga y profesora de Comunicación Publicitaria, Periodística y Nuevas Formas Publicitarias en la Universidad Carlos III de Madrid. Anteriormente, ha sido profesora de la Universidad de Alicante (2000-2006) y Visiting Scholar en el Department of Communication en UCLA (University of Califorina, Los Angeles, 2009). Imparte docencia en diversos postgrados y máster, y es una apasionada de las nuevas tendencias en el mundo de la comunicación y el marketing, tal y como se desprende de sus muchas publicaciones sobre el tema.

REDMARKA UIMA-Universidad de A Coruña - CIECID

Año VIII, Número 14, (2015), v I pp. 21-50

http://www.redmarka.net/ ISSN 1852-2300 
de recomendación de productos y marcas se ha extendido prácticamente a cualquier individuo, en tanto en cuanto interactúa con otros usuarios a través de estas plataformas, conversando también a propósito de sus experiencias como comprador y consumidor. Además, blogs y espacios como Twitter o Instagram han motivado la aparición de un nuevo perfil de prescriptores, líderes de opinión a los que las marcas recurren para multiplicar el alcance de sus acciones comunicacionales. En este artículo se analiza en qué consiste el marketing de influencia así como se describen las normas deontológicas y legales que anunciantes y agencias deben tener en cuenta a la hora de poner en marcha acciones publicitarias con influencers a través de redes sociales.

Palabras clave: Marketing; Comunicación; Publicidad.

\begin{abstract}
Advertiser figure has been one of the resources most widely used in advertising throughout its history. However, with the popularization of social networks, power of recommendation of products and brands has spread practically to anybody, insofar individual interacts with other users through these platforms, also talking concerning his/her experiences as buyer and consumer. In addition to this, blogs and platforms such as Twitter or Instagram have motivated the emergence of a new profile of prescribers, opinion leaders who brands resort to with the aim of multiplying the reach of their communication actions. This article focuses on what influence marketing is and which are its characteristics as well as describes the legal and ethical rules advertisers and agencies must take into account to perform advertising campaigns with influencers via social networks.
\end{abstract}

Keywords: Marketing; Communication; Advertising.

\title{
Sumario
}

1. Introducción. 2. La figura del prescriptor en publicidad. tipos de prescriptores. 3. El marketing de influencia en el actual panorama de comunicación. 4. Legalidad y deontología del marketing de influencia. 5. Conclusiones. 6. Notas. 7. Referencias bibliográficas.

REDMARKA UIMA-Universidad de A Coruña - CIECID 


\title{
1. INTRODUCCIÓN
}

El conocimiento de las características y los comportamientos de los consumidores a los que se dirige la publicidad de productos y servicios ayuda a establecer estrategias de segmentación de mercado gracias a la correcta identificación del público objetivo, de tal manera que el anunciante lleve a cabo un marketing diferenciado y oriente sus acciones comunicacionales hacia el mercado, permitiéndole actuar con realismo, eficacia y economía (García, 2001, p. 165).

El receptor, individuo objetivo de la comunicación, es el elemento clave del éxito de una campaña publicitaria (Díez \& Marín, 1999, p. 397). Como afirma García (2001, p. 164):

\begin{abstract}
"la esencia de la publicidad consiste en saber determinar quiénes son las personas a las que debemos dirigir cada uno de los anuncios y obrar en consecuencia, emitiendo mensajes comprensibles, significativos, estimulantes, sintonizados con ellas e insertados en los medios adecuados".
\end{abstract}

Las particularidades del consumidor del siglo XXI y de entornos colaborativos como las plataformas digitales hacen que ya no baste con una serie de datos relativos a sus características sociodemográficas sino que, además de éstas, se requiere una descripción en profundidad desde los puntos de vista psicológico (actitudes, intereses, necesidades, motivaciones, etc.), social (estilos de vida, grupos de referencia, valores, etc.) y comportamental (comportamientos y hábitos de compra y consumo).

En este sentido, una de las variables externas que contribuyen a la hora de definir a los individuos como seres sociales objeto de una acción comunicacional, en tanto en cuanto influye en su comportamiento como consumidores y compradores,

REDMARKA UIMA-Universidad de A Coruña - CIECID 
es el grupo referencial. Familia o amigos son grupos de referencia que, entre otras funciones, fomentan la formación del autoconcepto, gracias en parte a aquellos productos y servicios que el grupo utiliza.

La experiencia de otros individuos en su relación con bienes, servicios y marcas es tenida en cuenta dentro de los miembros de un grupo referencial, ejerciendo un poder prescriptor. La identificación o pertenencia a un grupo se consolida a través de una serie de valores comunes, en muchas ocasiones atribuidos a ciertos productos y marcas, hasta tal punto que los grupos de referencia son un ejemplo de que las opiniones de los propios individuos a través del boca-oreja sigue siendo, a día de hoy, la fuente de información y el canal de recomendación más fiable y eficaz entre consumidores y compradores ${ }^{1}$. Una recomendación sobre una marca por parte de alguien que conocemos puede influir en nosotros mucho más que cualquier campaña de marketing, como corroboran diversos estudios ${ }^{2} y$, en este sentido, Internet se convierte en uno de los canales que más influye en las decisiones de compra.

La eclosión de las redes sociales y la posibilidad que los entornos 2.0 han ofrecido a los usuarios a la hora de compartir sus opiniones, también en su rol de compradores y consumidores, ha hecho que, lejos de mermar, el boca-oreja se haya incrementado, especialmente cuando se trata de compartir la insatisfacción con algún producto o experiencias negativas con alguna marca. No obstante, la satisfacción también se propaga y, si el usuario está contento con algo que ha comprado o contratado, también lo compartirá con sus allegados; todos somos influencers gracias a las redes sociales.

Con un $90 \%$ de internautas como usuarios y dos de cada tres siguiendo a marcas a través de estas plataformas (cuatro de cada diez de forma activa) ${ }^{3}$, las redes sociales juegan hoy en día un papel clave en las estrategias de marketing, comunicación y publicidad.

El boca-oreja (Word-Of-Mouth), rebautizado como i-Boca-Oreja (Word-Of-iMouth) con los espacios digitales, es la mejor publicidad y, por este motivo, las empresas deben poner todo su empeño en forjarse una buena reputación digital y gestionar la conversación en entornos colaborativos a propósito de sus marcas con 
cercanía, transparencia e inmediatez, atendiendo a las críticas para mantener la confianza de sus clientes actuales y no perder clientes potenciales.

La lealtad del cliente con una marca depende de la satisfacción, la repetición de compra y, especialmente, de la recomendación, que se sitúa en el nivel más alto de vinculación emocional (Best, 2007, p. 20).

Cuesta también destaca que la fidelidad del cliente mucho tiene que ver con la labor de apostolado (2003, p.154), es decir, con la prescripción: un cliente fiel no es sólo aquel que repite transacciones, sino el que por encima de todo se siente satisfecho y orgulloso, y así se lo cuenta a los demás. Celaya (2008, p. 227) aconseja que la aplicación de herramientas participativas "es muy interesante en procesos de fidelización de clientes, ya que permite a nuestros "evangelistas" compartir su conocimiento y experiencia con los demás".

Las marcas ansían aprovechar la viralidad que favorecen las redes sociales con estrategias que buscan propagar su mensaje multiplicando exponencialmente su alcance, basándose en las recomendaciones de los usuarios. Afirma Castelló (2010, p. 94):

"En la actualidad, y frente al descenso que sufre la publicidad convencional en términos de credibilidad, está demostrado que la alternativa más fiable para una buena estrategia de marketing es la generación de recomendaciones entre consumidores, a través de estrategias de Marketing Participativo".

Para Del Pino, Castelló y Ramos-Soler (2013, p. 184), "la reputación de una marca está, hoy más que nunca, en manos del consumidor (crosumer, prosumer, persumer, fansumer) quien, gracias a los medios sociales, difunde y comparte sus opiniones y experiencias a propósito de empresas, marcas y productos".

El consumidor actual, fansumer o cliente apóstol (Chiesa de Negri, 2005, p. 101), tiene a su disposición plataformas en las que expresar su predilección por las marcas. Los anunciantes son conscientes de esta realidad y, por este motivo, han extrapolado el recurso a expertos, líderes de opinión o famosos como estrategia de apostolado, tan habitual en publicidad tradicional, a las plataformas digitales, para aprovechar el gran poder de prescripción y recomendación que tienen estos

REDMARKA UIMA-Universidad de A Coruña - CIECID 
testimoniales. La marca busca generar confianza, empatía y credibilidad entre el público a través de estos consumidores influyentes.

Como sostienen Agrawal y Kamakura (1995, p. 56), el uso de las celebridades en comunicación incrementa la credibilidad de los mensajes, aumenta el recuerdo y el reconocimiento de las marcas anunciadas, mejora la actitud hacia la organización que vende el producto, e incluso incrementa la probabilidad de compra.

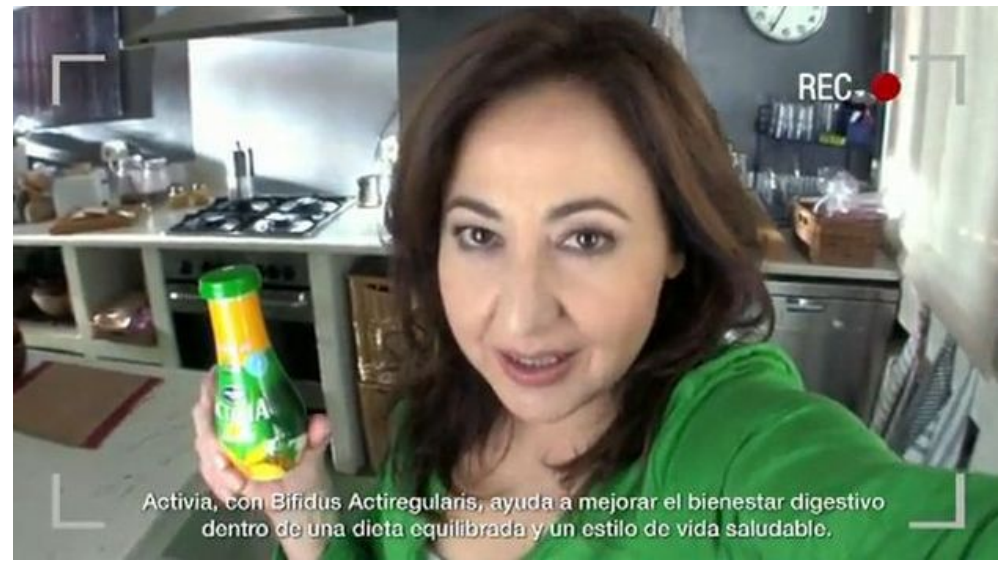

Figura 1. La actriz Carmen Machi anunciando Activia de Danone

La asociación de un producto o una marca con un personaje famoso se basa en una dimensión aspiracional de la audiencia y en mecanismos de identificación de ésta con el personaje que ayudan a la formación del autoconcepto ideal. El famoso se presenta así como representante de las inclinaciones del target, sus gustos y preferencias previamente identificadas en la investigación de ese nicho de mercado, así como de las cualidades del producto, evitando que "canibalice" al producto.

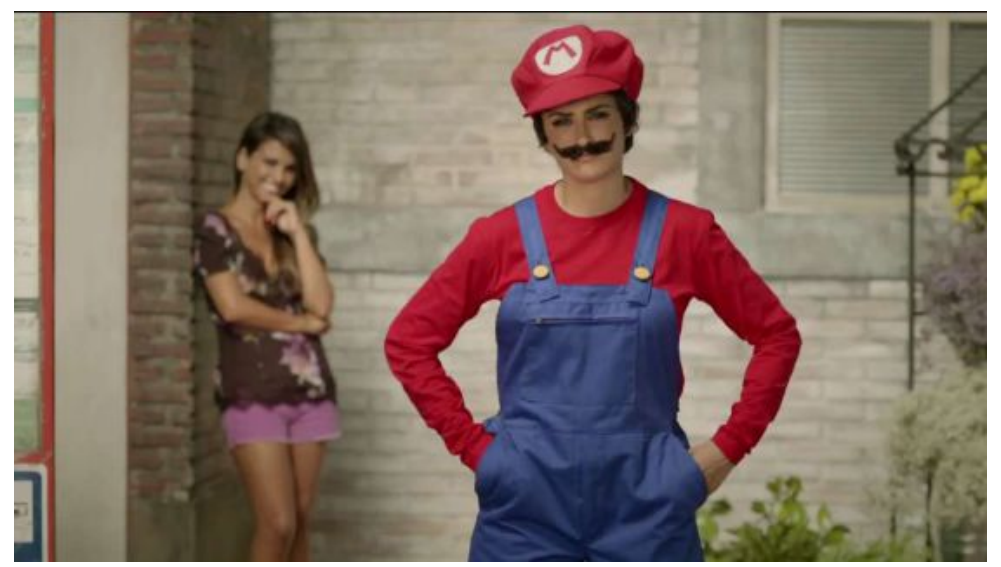

REDMARKA UIMA-Universidad de A Coruña - CIECID 
Figura 2. Spot promocional de New Super Mario Bros. 2 para Nintendo 3DS en 2012 con Penélope Cruz y Mónica Cruz

Un ejemplo de esta tendencia a asociar marcas con líderes de opinión o personajes conocidos públicamente a través de espacios de la Web 2.0 es el fenómeno de las blogueras de moda, que constantemente aconsejan en sus blogs y espacios en redes sociales productos de marcas que se los prestan o regalan buscando lograr gracias a sus audiencias máxima visibilidad con mínima inversión. Estas "it girls", a quienes se les presupone independencia y credibilidad, se han convertido en nuevas prescriptoras imprescindibles para la estrategia de marketing de cualquier marca de moda, llegando a cobrar hasta 450 euros por tuit y 12.000 euros por amadrinar un evento ${ }^{4}$.

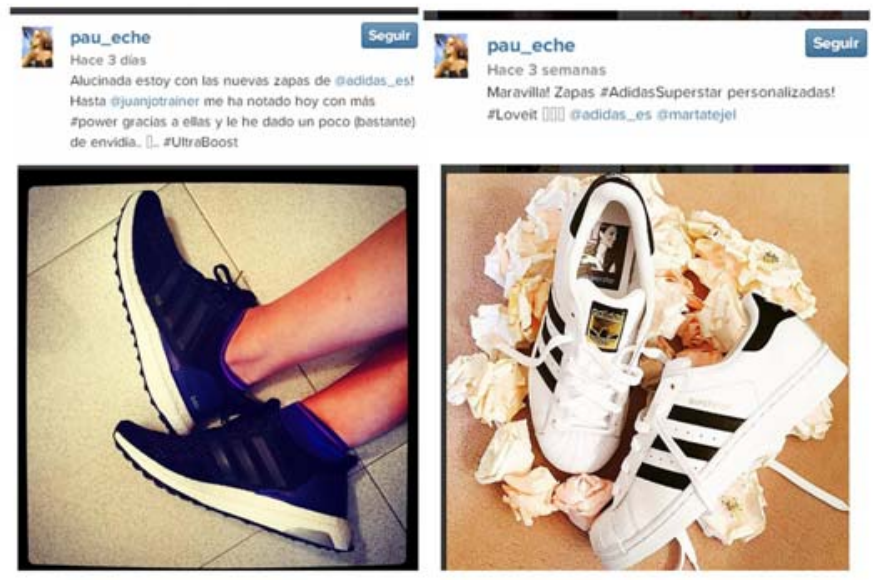

Figura 3. Publicaciones de la actriz y bloguera Paula Echevarria en Instagram sobre productos Adidas

Esta práctica ha dado lugar al llamado marketing de influencia, en el que se fusionan las redes sociales como espacios publicitarios con el recurso a los usuarios, como los líderes de opinión o los personajes famosos, como prescriptores o influencers, personas influyentes a los que las marcas dirigen sus esfuerzos comunicativos para, a través de ellos, llegar a más consumidores potenciales.

Para el estudio "Top Tendencias 2015" ${ }^{5}$ de IAB Spain, 2015 es el año de los Influencers y los Brand Ambassadors: en el primer caso, se trata de personajes famosos a los que las marcas buscan con el objetivo de asociar a ellos su imagen corporativa para lograr un buen posicionamiento entre los consumidores. En el

REDMARKA UIMA-Universidad de A Coruña - CIECID 
segundo caso, son los influencers los que buscan a marcas afines para representarlas.

\section{LA FIGURA DEL PRESCRIPTOR EN PUBLICIDAD. TIPOS DE PRESCRIPTORES}

"Yo sí como patatas". En 1958, uno de los eslóganes publicitarios más pegadizos de aquella incipiente publicidad era pronunciado por un actor que, ataviado con una bata médica y mirando directamente a cámara, emitía esas cuatro palabras en un intento de concienciar a la sociedad de la importancia de incluir este tubérculo en nuestra dieta. Tras él, una madre y un deportista hacían lo propio, aderezando su discurso con una pegadiza canción o jingle para contribuir a fijar en la mente del telespectador las bondades del producto. Eran los primeros prescriptores publicitarios en España (García \& Fernández, p. 1990), figuras anónimas que bajo un rol determinado, trataban de influir en la sociedad para inculcar, en este caso, un hábito relacionado con la salud. En el terreno del marketing, un prescriptor es alguien que, de forma individual, por su personalidad o por su pertenencia a una entidad, genera corrientes de influencia por sus opiniones, valoraciones y decisiones de compra. En su blog Vilma Núñez ${ }^{6}$ define al prescriptor como "aquella persona o personalidad que tiene la habilidad de influir en un determinado público cuando comparte su opinión o valoración sobre algún producto, servicio o marca". Como espectadores, bajamos la guardia racional ante alguien a quien admiramos, cuya presencia ante un producto nos coloca en un estado de vulnerabilidad tal que de forma no consciente se activan los mecanismos emocionales en los que transferimos todo tipo de bondades al producto, por el mero hecho de una asociación positiva. De forma ilusoria y guiados por el subconsciente el discurso permea y es retenido en la mente del consumidor. 


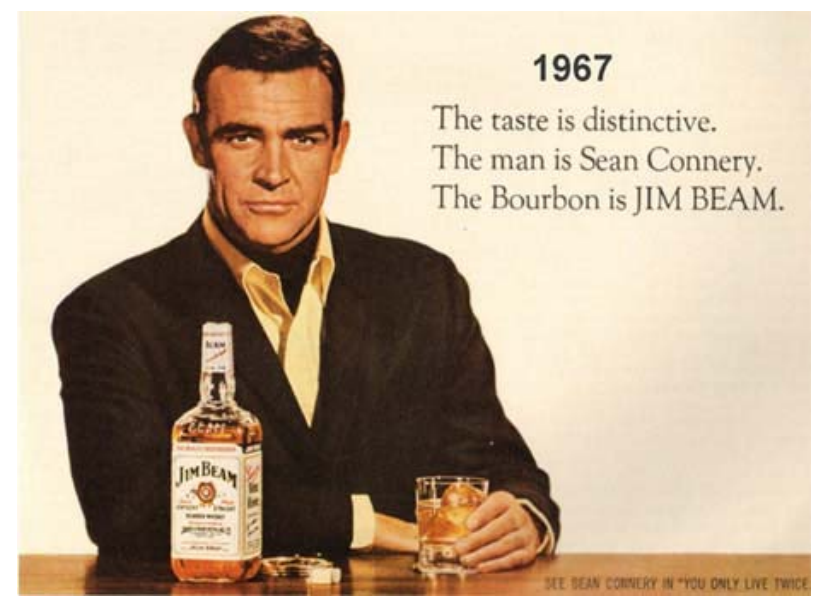

Figura 4. Sean Connery prestando su imagen a Jim Beam Bourbon en la década de 1960

Desde aquella incipiente publicidad a la era actual de las redes sociales, el espectro de posibilidades para sacar el máximo partido de este poder de influencia se ha multiplicado hasta el infinito. Identificar a los líderes de opinión que pueden ayudar a conectar a una marca de forma natural y espontánea con su público objetivo en este momento de saturación publicitaria, es algo de valor incalculable. Desde celebridades -en un extremo de la escala- a amigos -en la otra-, pasando por gente que deja su impronta en diferentes canales de Internet, desde YouTube a Twitter, el abanico de opciones es amplio, y controlar ese poder de influencia ha dejado de ser una opción para las marcas para pasar a ser casi una asignatura obligatoria. Planificar en la medida de lo posible el poder de influencia y contar con las herramientas para rentabilizarlo es igualmente mandatorio.

Fuera de nuestras fronteras, y volviendo al origen en materia publicitaria del poder de prescripción, resulta digna de mención la capacidad de influir desde los remotos años treinta en un caso y un producto tan concreto como el tabaco y los personajes famosos que prestaban su imagen para esta relación. 


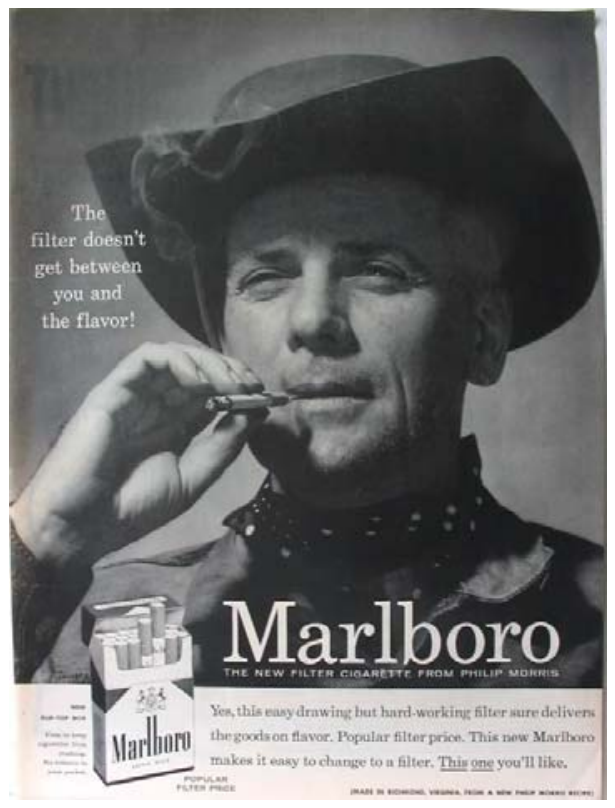

Figura 5. Johnny Cash y Marlboro en una imagen de la década de 1960 El equipo formado por tabacalera, publicidad, cinematografía y famoso funcionó durante años aportando pingues beneficios a las multinacionales, en vanguardia, marcando tendencias, abriendo camino, en ocasiones con burdos mecanismos de manipulación dignos de estudio ${ }^{7}$. Eslóganes antiguos de campañas publicitarias de tabaco de esa época ponen de manifiesto, entre otros, planteamientos en los que la salud juega un importante papel -médicos fumando y recomendando una marca de tabaco por encima de las demás, por ejemplo-. En otras ocasiones se evidencia cómo la publicidad es un reflejo de la sociedad y una influencia sobre los tiempos (Jiménez, Olarte \& Reinares, 2008, p. 29), como en los casos en los que sumamos este poder de prescripción al importante rol que el hombre desempeña en la sociedad de esta época, sexista y relegando a la mujer a un segundo plano. Particular mención merece en este sentido la campaña de un hombre anónimo fumando y exhalando una bocanada de aire sobre el rostro de la mujer que la acompaña en el fotograma publicitario. 


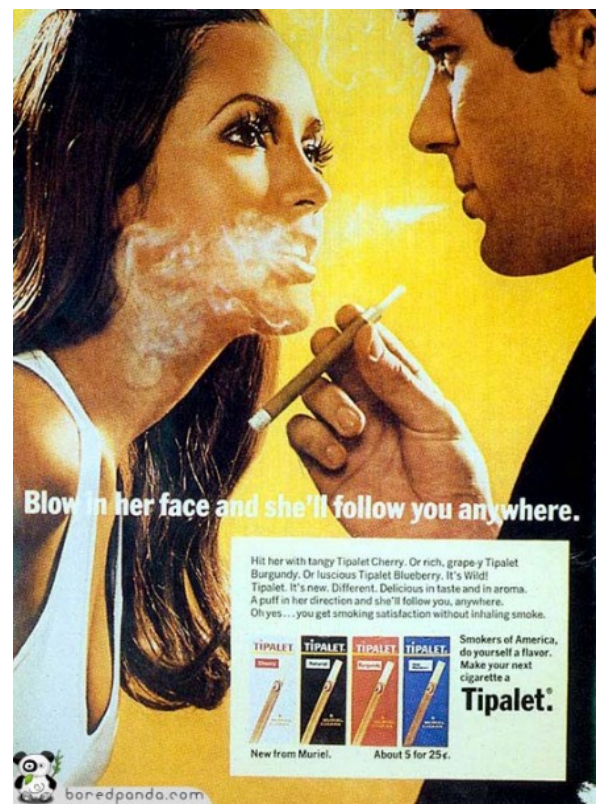

Figura 6. Campaña de cigarrillos Tipalet y su particular manera de entender la persuasión publicitaria, bajo la posible explicación de los diferentes sabores de tabaco de la marca: cereza, arándano y uva, entre otros (años 60) Un parámetro de vital importancia a considerar al analizar la figura del prescriptor publicitario es apostar por una verdadera y creíble relación en primera instancia entre el producto y el propio famoso. Solamente si ese vínculo es sostenible, veraz y suficientemente sólido se podrá fijar una relación biunívoca, de mutua influencia, que trascenderá al universo social para, a su vez, influenciar en el receptor, llamémosle a éste público objetivo, usuario o simplemente consumidor. En la historia de la comunicación publicitaria encontramos casos palmarios de intentos de relación frustrada, como la compañía farmacéutica americana de analgésicos Datril, que tras un proceso de negociación arduo, acabó convenciendo al agente del actor John Wayne para que éste le prestara su imagen. Acostumbrado el público a las proezas de Wayne y a su particular forma de abordar el peligro, no resultó del todo creíble su manera de pelear contra el dolor de cabeza, no favoreciéndose el proceso inconsciente de transferencia, identificación e influencia necesarios para, en este caso, activar las ventas.

Otro de los factores importantes en la matriz en este proceso de relación, es el de la confianza. En la era de la socialización de las audiencias (Aguado, 2015, p.110), en la gestión de marca no puede pasarse por alto la importancia de un término sin 
el cual nada en este sentido sería viable. El proceso de construcción de confianza es vinculante y, como valor, fundamental tenerlo presente en cualquiera de sus versiones. Así, aquellos usuarios que dan su opinión sobre individuos, empresas o productos, ayudan a tomar decisiones al resto, actuando los primeros como prescriptores. Éstos contribuyen a formar los llamados grupos de aspiración (Baena, 2011), es decir, los grupos a los que a su vez nos gustaría pertenecer por una razón u otra; la confianza resulta ser un componente consustancial en este proceso.

Delimitados los ejes sobre los cuales se asienta el poder de influencia credibilidad, en primera instancia, confianza y poder aspiracional- hay otros valores a sumar a esta cadena y que se pueden detectar y analizar en los múltiples ejemplos que la historia de la publicidad, desde la más antigua a la actual; credibilidad, fiabilidad, independencia y estilo propio son parámetros a los que se aspira de forma inequívoca en los distintos modelos en los que esta relación es evidente.

Independientemente de la forma que adopten los discursos con los que se pretende influir, el prescriptor publicitario de antaño y el llamado influencer del siglo XXI resultan ser una misma figura a la que los avances tecnológicos y un mundo globalizado gracias a la Red dotan de un inusitado poder que el universo del marketing y la publicidad no ha pasado por alto en ningún momento de la historia. La diferencia es la forma en que se rentabiliza en la actualidad esta capacidad de fijar tendencias, que abarca desde la posibilidad de generar conciencia social para un fin concreto - el futbolista José María Gutiérrez "Guti", utilizado por la empresa Eco Vidrio para extender la importancia y la necesitad medioambiental del reciclaje- al mero interés comercial de querer aumentar las ventas de un producto. En el primer caso, hablamos de una notoria campaña de marketing de influencia orquestada para incendiar las redes sociales, que tiene su origen en un controvertido tuit: “¿Vosotros perdéis el tiempo en reciclar vidrio? Yo no", preguntaba el futbolista animando a los internautas a respuestas que no se hicieron esperar desde su cuenta en Twitter (@GUTY14HAZ). Desde la cuenta de la compañía (@ecovidrio) se contraatacó creando un hashtag para la ocasión: \#gutirecicla. Cuando todo se descubre -de la misma forma, con un nuevo tuit 
enlazado a un vídeo ${ }^{8}$ en donde el propio protagonista da la explicación pertinente y la empresa justifica la campaña- miles de usuarios habían dado las razones por las que llevan a cabo este cívico gesto. En este ejemplo, encontramos tres ingredientes necesarios para poder hablar de influencia en estado puro: un mensaje cargado de contenido, una personalidad pública y un contexto, redes sociales; si bien el peso de cada uno de los componentes de este conjunto es equitativo, todo parece indicar que el resultado de la campaña no habría sido el mismo sin la figura del prescriptor o influencer.

Otro notorio caso de marketing de influencia relacionado con una figura relevante o celebrity, en este caso también un deportista, fue el protagonizado por el tenista David Ferrer y Samsung Galaxy 4. Aprovechando su participación en el Mutua Madrid Open 2014, patrocinado por la empresa surcoreana, Ferrer lanzaba un tuit en su perfil de la red social que contenía el siguiente mensaje:

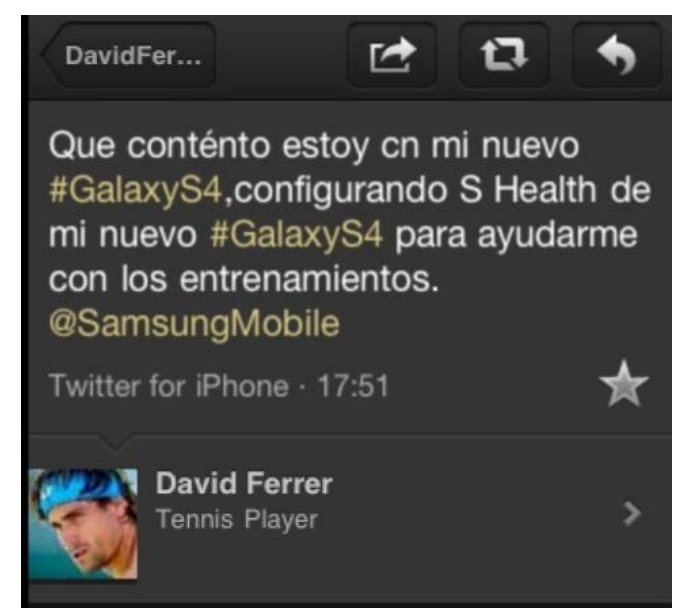

Figura 7. Tuit de David Ferrer sobre el móvil Samsung Galaxy S4

El problema, tal y como se deduce de la imagen, es que esas palabras eran lanzadas desde el terminal de la competencia; junto al mensaje, "via Twitter for iPhone". A los pocos minutos el mensaje era eliminado de la red social, pero para entonces su repercusión ya era una realidad ${ }^{9}$. Esta es la máxima evidencia de lo importante que resulta cuidar al máximo la acción realizada para que no revierta negativamente tanto en la empresa como en el influencer.

La compra de tuits es, pues, una práctica muy empleada por las marcas, ya que permite generar mucho ruido en Twitter y asegura un gran alcance $y$ difusión gracias a los miles o millones de usuarios que siguen a un personaje

REDMARKA UIMA-Universidad de A Coruña - CIECID 
conocido. El precio medio de un tuit está entre 20 y 30 mil euros,, pero resulta de vital importancia que el mensaje del influencer encaje con el target así como adoptar en el tuit el tono habitual del influenciador. De acuerdo con The Huffington Post $^{10}$, otras personalidades como Jared Leto pueden percibir hasta 13.000 dólares por publicar un tuit patrocinado. En este sentido, seleccionar los perfiles simplemente en función del número de seguidores en redes sociales y/o las visitas mensuales que tenga el blog es un error; por ello, resulta de vital importancia conocer la actitud de los influenciadores ante otros lanzamientos o acciones de marcas de la competencia, por ejemplo, analizar el tipo de contenido que comparten, observar las características de su comunidad o la forma en que sus seguidores conversan. Sea como fuere, en la relación marca-influencer las dos partes tienen que beneficiarse de colaborar conjuntamente.

Al hablar del prescriptor-influencer del siglo XXI, debemos atender a la siguiente clasificación. En primer lugar, la celebridad o celebrity -el rostro conocido y famoso para el gran público-. En el ejemplo de la campaña del vidrio, nos encontramos ante un líder social que destaca en su disciplina, el deporte, y aprovecha esta coyuntura para imponer su criterio en las redes sociales. Los blogs de famosas como Paula Echevarría o Sara Carbonero también serían un ejemplo de este tipo de influencer, teniendo en cuenta que son los que requieren más inversión para una segmentación difícil de realizar, ya que sus seguidores son muy dispares y no están tan delimitados.

En segundo lugar, hablamos de la figura del experto, alguien a quien los usuarios identificamos como especializado en un tema concreto, en donde prevalece el criterio cualitativo por encima del cuantitativo: la audiencia no va a ser tan numerosa pero sí muy específica, y ese poder de prescripción y credibilidad resulta ser de todo punto útil para la empresa, en lo que concierne a factores como la recomendación y la influencia en círculos estratégicos de interés.

A los dos tipos de prescriptores anteriores sumamos la figura del blogger propiamente dicha; se trata de alguien con conocimiento sobre su sector de actuación, acceso a redes sociales con miles de seguidores y que aporta un material alternativo que puede servir de apoyo a la marca. Este personaje decide 
individualmente lo que desea hacer, pudiendo ser contratados para hablar de una marca o un determinado producto.

Los dos modelos de prescriptor restantes con que nos encontramos en la actualidad son el periodista y el consumidor. El primero es activo y conocedor de muchos ámbitos, con manejo y gran poder de influencia de los canales de comunicación que llegan al gran público. Por su parte, el consumidor es alguien con un altísimo poder de influencia en sus círculos cercanos, a quien se debe fidelizar para convertir en usuarios de una marca. Si se consigue, su poder es inusitado ${ }^{11}$.

En suma, podemos enmarcar al prescriptor como la figura central de un marketing que bien gestado permite captar seguidores aportando valor. Al final, en la base de todo este entramado encontramos la esencia de la comunicación, "comunicar, siempre comunicar", tal y como señalan Pintado \& Sánchez (2012, p. 34).

Es la constatación del trasvase del poder de los vendedores de siempre a los compradores de la época actual, (González; Salutregui \& Sánchez, p. 2004), gracias al factor de la recomendación. Ésta, a su vez, llega de la mano del prescriptor, del que ha existido siempre fuera del mundo digital, al de la actualidad u online. Una herramienta de un poder difícil de calcular, que en la actualidad precisa de un meticuloso aprendizaje en su manejo en lo concerniente a la Red.

\section{EL MARKETING DE INFLUENCIA EN EL ACTUAL PANORAMA DE COMUNICACIÓN}

La estrategia colaborativa llevada a cabo entre empresas y personas influyentes o relevantes de un determinado sector de manera que ambas se beneficien de forma conjunta recibe el nombre de marketing de influencia ${ }^{12}$. El término en sí surgió en los años 60, en boca de Daniel Edelman, para denominar el poder que ejercían los famosos y celebridades sobre los consumidores, y la capacidad que éstos tenían para traducir recomendaciones u opiniones en ventas, y básicamente está basado en la capacidad de identificar líderes de opinión, ya sea basándonos en el número de seguidores, de likes en las fotos, de comentarios, o de todo a la vez, que pueden ayudar a una marca a conectar de forma natural y espontánea,

REDMARKA UIMA-Universidad de A Coruña - CIECID 
no invasiva, con su público objetivo. Este tipo de usuarios suelen generar una comunidad a su alrededor con un fuerte engagement y son fácilmente detectables. Consiste, en suma, en la capacidad de identificar a esos líderes de opinión prescriptores de una marca- para conseguir alcanzar al público objetivo de un modo directo y natural.

Una vez más, se pone de manifiesto cómo la novedad en relación a este tipo de marketing no reside tanto en su naturaleza en sí, como en el uso que de él se lleva a cabo en la actualidad gracias los nuevos parámetros y las nuevas reglas de la comunicación.

En el centro de esta compleja y rentable actividad, se halla la figura anteriormente descrita; identificar a los influencers con mayor poder de prescripción es el primer paso a dar por parte de las empresas y marcas que barajan dentro de la estrategia de marketing de contenidos la forma de gestionar de manera rentable esta relación. La manera en que se genera contenido favorable a las empresas puede ser muy variada, oscilando desde un post en un blog a una campaña masiva, estructurada y organizada habiendo calculado previamente el alcance que puede suponer la colaboración con el o los influencers; en este sentido, el primer paso a seguir sería por tanto identificar a los usuarios -del tipo que sean- con más poder de prescripción dentro del sector. Cualquier usuario puede actuar como impulsor de contenidos -cabe recordar en este punto que el consumidor, cualquiera de nosotros, es uno de los cinco tipos de influenciadores que hay-. Desde los de mayor influencia a los de menos, el primer paso a seguir por una empresa que quiera adoptar el marketing de influencia como estrategia debe considerar unos y otros en su influencers map.

Otra de las grandes bondades del marketing de influencia es que contribuye a generar contenido orgánico o no pagado sobre la marca, debido a comentarios que se desprenden de las redes sociales o por los a los posts subidos a blogs y publicados por los influencers. Las cifras que se manejan de acuerdo a los efectos del marketing de influencia en el mercado evidencian que nos encontramos ante una realidad que las empresas y organizaciones no pueden obviar. Así, de acuerdo con el "Informe Augure sobre el estatus del marketing de influencers"13, cada vez más marcas emplean esta técnica, y muchas ya lo están planificando en

\section{REDMARKA UIMA-Universidad de A Coruña - CIECID}


sus estrategias. Para los profesionales del marketing y la comunicación, el papel que juegan los influenciadores es de todo punto estratégico para una empresa, y en especial resaltan situaciones como promoción y distribución de contenido (57\%), organización de eventos/webinars (50\%), lanzamientos de producto (76\%), y gestión de crisis (44\%) como aquellas en las que resulta de vital importancia contar con un equipo especialmente preparado para ello.

Zaremba $^{14}$ sintetiza los grandes beneficios para la marca que supone este tipo de marketing, y que van desde el poder de recomendación -dejar que sea la Red la que hable de los beneficios-, pasando por el acceso alternativo a grandes audiencias sin olvidar la posible influencia que se puede ejercer en círculos estratégicos, es decir, grupos de posibles influenciadores muy concretos y especialmente motivados para con nuestra marca o empresa. Estos beneficios serán tales bajo unas máximas, entre las que hay que considerar de forma imperativa, entre otras, que la acción planeada sea creíble y no contravenga la ideología del influenciador -a algo que puede parecer obvio pero no lo es tanto si consideramos lo sucedido con celebrities como Ferrer o Winfrey-, que el influenciador no vea peligrar su credibilidad - que se sienta cómodo con la estrategia planteada- y que el influenciador crea suficientemente en la marca. Esa credibilidad traspasará la pantalla -cualquiera que ésta sea-; así, Rafa Nadal es uno de los tenistas más importantes de todos los tiempos pero su relación con alimentación infantil -por señalar un ejemplo de naturaleza ajena a su ámbito- no parece muy creíble.

De igual forma, y dado que en todo momento estamos poniendo de manifiesto estrategias de marketing pull, en las que es el consumidor el que de forma voluntaria se acerca al contenido por el atractivo de éste, el lenguaje adoptado por el influencer no debe denotar agresividad comercial, de lo contrario, la tendencia es la de rechazar el mensaje. La comunicación en las redes sociales tiene una naturaleza que dista de la publicidad convencional. Por último, y en la misma línea de importancia, el mensaje debe formar parte del contexto de una historia con entidad, con peso, que invite a la interacción, como en el caso de la campaña descrita protagonizada por Guti, en donde se daban razones congruentes para invitar a la acción. 
Una de las premisas para que el marketing de influencia resulte efectivo es crear contenidos en los que la imaginación sea un componente relevante y la distribución del contenidos se lleve a cabo de manera diferente, con una estrategia premeditada, reposada, y con una planificación en donde se pueda prever -dentro de lo posible, habida cuenta de que por la propia naturaleza de las redes sociales los efectos en éstas son, en la mayoría de las ocasiones, poco previsiblesdedicación, cálculo de consecuencias y efectos del feedback. En este sentido, Núñez sintetiza la estrategia del marketing de influencia de la siguiente manera:

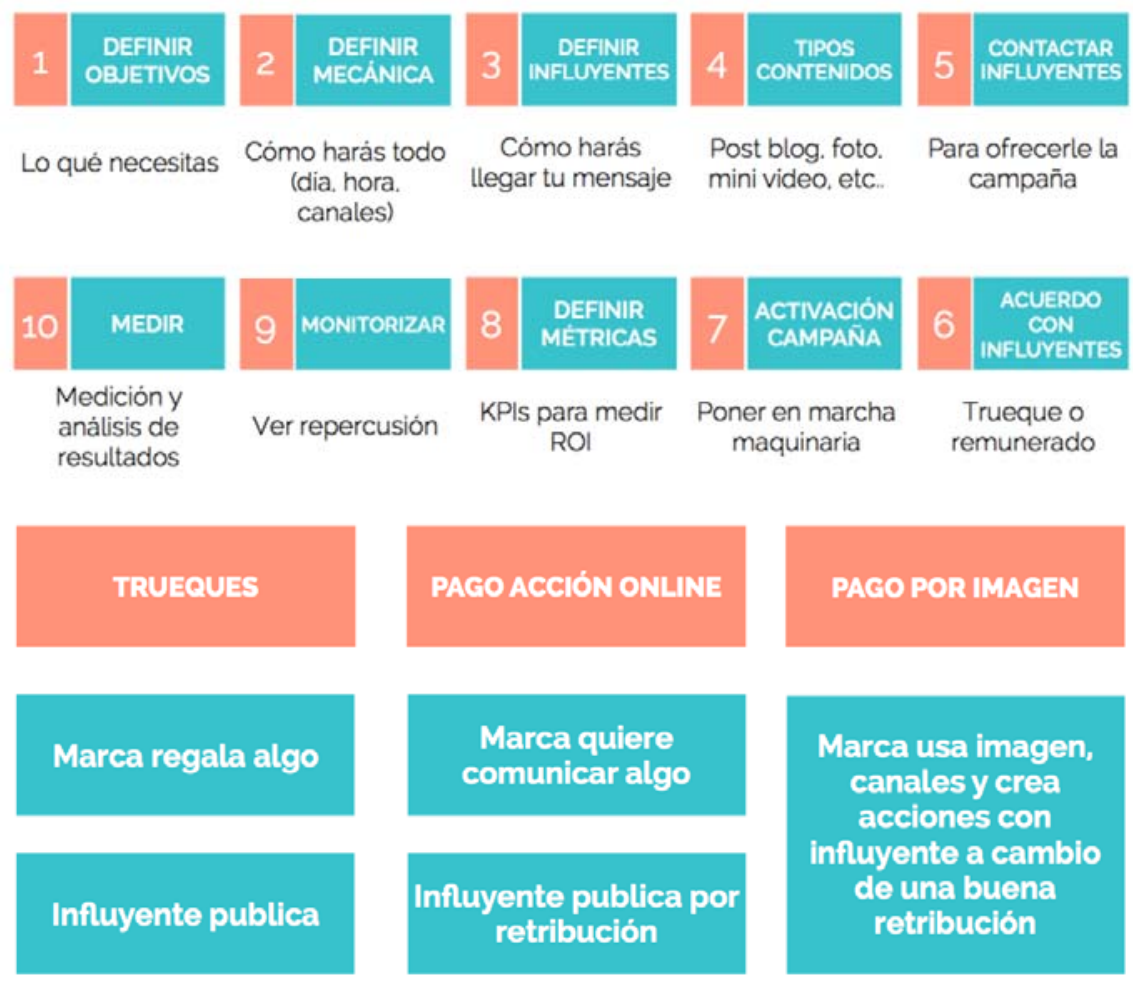

Figura 8. Estrategia de marketing de influencia según Vilma Núñez ${ }^{15}$

Los casos de éxito del marketing de influencia a nivel nacional e internacional son muy numerosos. Fuera de nuestras fronteras, y si tomamos como parámetro de referencia los millones de visitas de los usuarios, merece especial el caso de Kia Motors y su concepción de este tipo de marketing. El Socia Media Manager de esta compañía considera que esta disciplina tiene como base el mismo funcionamiento que una cita; después de un primer contacto, hay que mantener la comunicación para que la relación surja. Siguiendo esta premisa, la empresa del rubro lanzó Kia Social Club, donde reclutan a bloggers influyentes, dándoles

REDMARKA UIMA-Universidad de A Coruña - CIECID

Año VIII, Número 14, (2015), v I pp. 21-50

http://www.redmarka.net/ ISSN 1852-2300 
espacio para que cuenten sus historias y sin dejar de mantener el contacto. Dando espacio a categorías como "estilos de vida de la mujer" o "crianza de hijos", la marca logró entablar relaciones con casi doscientos partidarios logrando así un engagement traducido en 130 millones de visitas.

En el ámbito del marketing turístico las acciones de promoción con líderes de opinión o influenciadores digitales han popularizado los conocidos como blogtrips. Se trata de eventos cuyo objetivo es la promoción de un destino turístico en los que se congrega a blogueros influyentes para que disfruten durante su estancia de la oferta turística de ese emplazamiento y así difundan su experiencia en sus espacios en redes sociales.

Por último, consideramos importante la mención de un sonado caso de marketing de influencia dentro de nuestras fronteras. "Bajo la misma estrella" es el título en castellano de la famosa novela de John Green, una obra que ha permanecido como número uno en ventas en EEUU desde que se lanzó a principios de 2012. La editorial española Nube de Tinta, usó la red social Twitter de una original y sencilla manera. Dirigida a los lectores más jóvenes, decidieron contar con los actores Angy Fernández y Maxi Iglesias para la promoción de la misma. Ambos llevaron a cabo un intercambio de tuits que no pasó desapercibido a los usuarios de las redes, y que se interpretó pronto como un flirteo que ambos terminaron aclarando. Misivas de la primera como "La gente se acostumbra a la belleza", tuiteó la actriz Angy Fernández (@angyfdz) con más de 500 mil seguidores, eran contestadas por Iglesias (@Maxi_Iglesias) con "Pues yo todavía no me he acostumbrado a ti". La conversación se desarrolló durante 3 días y generó multitud de interacciones entre los fans de los dos famosos, con favoritos, retuits y menciones $^{16}$. La acción quedó al descubierto el día de San Valentín de 2014, cuando ambos revelaron que estaban compartiendo frases de la novela, que ambos leían a la vez. 


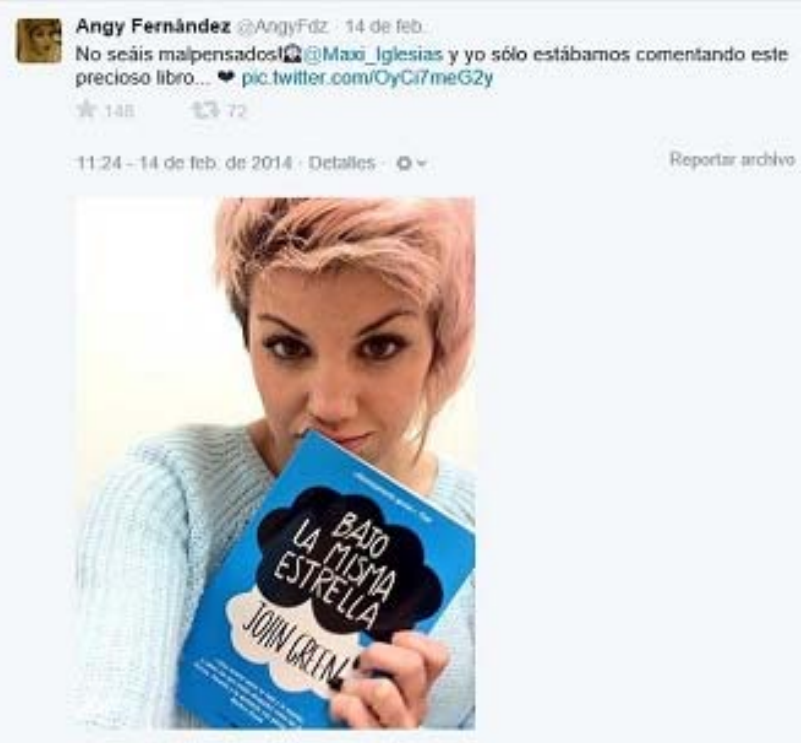

Figura 9. Tuit de @angyFdz sobre la novela "Bajo la misma estrella" Al albur de estos datos y ejemplos, resulta evidente que la comunicación en general y la publicidad de forma concreta, toma nuevas formas en la era de las redes sociales. Tomando como referencia el ejemplo anterior, en cualquier otro momento estos dos actores habrían protagonizado un spot publicitario para ser emitido en horario de máxima audiencia en todas las cadenas de televisión. Sin embargo, el marketing de influencia permite segmentar, llegar a los seguidores de ambos y dirigir la conversación sobre el objetivo, construyendo para ello un discurso exento de la agresividad comercial propia de la publicidad convencional.

\section{LEGALIDAD Y DEONTOLOGÍA DEL MARKETING DE INFLUENCIA}

Uno de los aspectos del marketing de influencia que más debate genera es la dimensión legal y ética de las acciones publicitarias basadas en influencers. De acuerdo con la legislación vigente, el consumidor debe poder distinguir entre lo que es publicidad y lo que es información, premisa que también se aplica a la publicidad digital, en general, puesto que ésta se rige por la misma normativa que la publicidad offline (la Ley 34/1988 General de Publicidad, con su modificación 29/2009, y la Ley de Competencia Desleal), así como la Ley de Servicios de la Sociedad de la Información y de Comercio Electrónico (LSSI). 
De acuerdo con la Ley 34/1988 General de Publicidad, uno de los cinco tipos de publicidad ilícita es la engañosa, es decir, la que de cualquier manera, incluida su presentación, induce o puede inducir a error a sus destinatarios, pudiendo afectar a su comportamiento económico, o perjudicar o ser capaz de perjudicar a un competidor.

Cuando la publicidad es engañosa por su forma hablamos de publicidad encubierta, induciendo a error al presentar apariencia informativa y no desvelarse su carácter publicitario, de manera que el consumidor cree que está ante contenido editorial. Los anunciantes deben desvelar inequívocamente le carácter publicitario de sus anuncios. Además, cuando la publicidad engañosa no sólo afecta al consumidor, sino también a la competencia, es también publicidad desleal, por lo que podemos decir que toda la publicidad engañosa es, consecuentemente, desleal.

El artículo 7 de la Ley de Competencia Desleal regula las omisiones engañosas, calificando de publicidad desleal aquella cuya información es poco clara, ininteligible, ambigua y no se ofrece en el momento adecuado o aquella que no da a conocer su propósito comercial cuando no resulte evidente por el contexto. El artículo 26 de esta Ley considera a las prácticas comerciales encubiertas como una práctica desleal con los consumidores, especificando que:

"Se considera desleal por engañoso incluir como información en los medios de comunicación, comunicaciones para promocionar un bien o servicio, pagando el empresario o profesional por dicha promoción, sin que quede claramente especificado en el contenido o mediante imágenes y sonidos claramente identificables para el consumidor o usuario que se trata de un contenido publicitario".

El artículo 26.2 añade a esto que:

"Para la determinación del carácter engañoso de los actos a que se refiere el apartado anterior, se atenderá al contexto fáctico en que se producen, teniendo en 
cuenta todas sus características y circunstancias y las limitaciones del medio de comunicación utilizado.

Cuando el medio de comunicación utilizado imponga limitaciones de espacio o de tiempo, para valorar la existencia de una omisión de información se tendrán en cuenta estas limitaciones y todas las medidas adoptadas por el empresario o profesional para transmitir la información necesaria por otros medios".

La Ley de Servicios de la Sociedad de la Información y del Comercio Electrónico (LSSICE) también destaca en su artículo 20 que:

"Las comunicaciones comerciales realizadas por vía electrónica deberán ser claramente identificables como tales y deberán indicar la persona física o jurídica en nombre de la cual se realizan. En el caso en el que tengan lugar a través de correo electrónico u otro medio de comunicación electrónica equivalente incluirán al comienzo del mensaje la palabra publicidad".

Por tanto, los mensajes en redes sociales publicados por famosos sobre marcas a cambio de una recompensa (económica o de otro tipo) podrían considerarse publicidad engañosa y, por tanto, ilícita, en tanto que publicidad encubierta al presentar apariencia informativa. Por otra parte, si calificamos a blogs y redes sociales como Twitter o Instagram como medios de comunicación, desde el punto de vista de la Ley de Competencia Desleal, nos encontramos con que las acciones de marketing de influencia con celebrities y líderes de opinión en las que no se especifica el carácter comercial de los mensajes pueden ser tachados de publicidad desleal. Y, si bien la LSSICE únicamente hace alusión explícita al envío de correos electrónicos comerciales, los mensajes publicitarios en plataformas digitales, también los publicados por influencers en blogs y redes sociales (entendidos como "otro medio de comunicación electrónica equivalente"), deberían incluir la palabra "publicidad". En este sentido, utilizar la abreviatura \#publi en los tuits publicitarios podría ser una solución fácil para cumplir con la normativa actual.

REDMARKA UIMA-Universidad de A Coruña - CIECID 
Desde el punto de vista deontológico, se entiende que cualquier iniciativa publicitaria que no cumple la legalidad no es ni ética ni honesta. Para la Asociación de Autocontrol de la Publicidad, la legislación publicitaria se basa en que nunca hay que abusar de la buena fe del usuario, insistiendo en que la publicidad encubierta "viola el principio de respeto a la legalidad, el requisito de autenticidad o la necesaria identificación como publicidad y la exigencia de veracidad".

La Asociación de Agencias digitales y Adigital plantean cinco reglas a la hora de tratar con influenciadores desde el punto de vista de la agencia ${ }^{17}$ : respetar la ideología del prescriptor, mantener la credibilidad, creer en la marca, integrar el mensaje en la comunicación habitual del influencer y procurar que el contexto dé sentido a la acción.

Plataformas como Twitter insisten en que es obligatorio revelar a los seguidores cuándo una actualización ha sido compensada o patrocinada, conscientes de que las campañas pactadas entre terceros al margen de su cartera de soluciones comerciales (tendencias, cuentas y tuits patrocinados) no les reportan beneficio alguno.

Como vemos, la legislación existente es aplicable al marketing de influencia, en tanto que acción publicitaria, sin que sea necesario un marco normativo específico, si bien la falta de estándares para indicar que se está difundiendo un mensaje comercial provoca el continuo incumplimiento de la normativa vigente. Además, resulta complicado demostrar que el prescriptor ha difundido un mensaje sobre determinada marca a cambio de algún tipo de remuneración.

Ante estas dificultades, no es de extrañar que no exista en España, a principios de 2015, ninguna resolución frente a la publicidad encubierta en las redes sociales. En países como Reino Unido y Estados Unidos de América los organismos reguladores encargados del control de la publicidad en los medios ya han intervenido ante denuncias de consumidores, fijando la obligatoriedad de incrustar las etiquetas, \#spon (de sponsored content), \#ad o \#advertisement para indicar que se trata de publicidad.

El jugador de fútbol Wayne Rooney ha protagonizado en Reino Unido dos campañas de marketing de influencia con diferente final para una misma marca: 
Nike. En el primer caso, el mensaje incluía la etiqueta de la campaña publicitaria de la marca deportiva (\#makeitcount) y un enlace a la página web, pero la resolución de The Advertising Standards Authority (ASA) estimó la reclamación contra el tuit al considerarlo publicidad encubierta e instó a Nike a retirar el controvertido mensaje, reclamando que se identificaran futuras campañas similares para evitar cualquier riesgo de confusión. Para el ASA, ni la estructura ni el contenido del tuit revelaban suficientemente su carácter promocional y, contrariamente, su diseño y tono hacían pensar que se trataba de un mensaje personal y espontáneo.

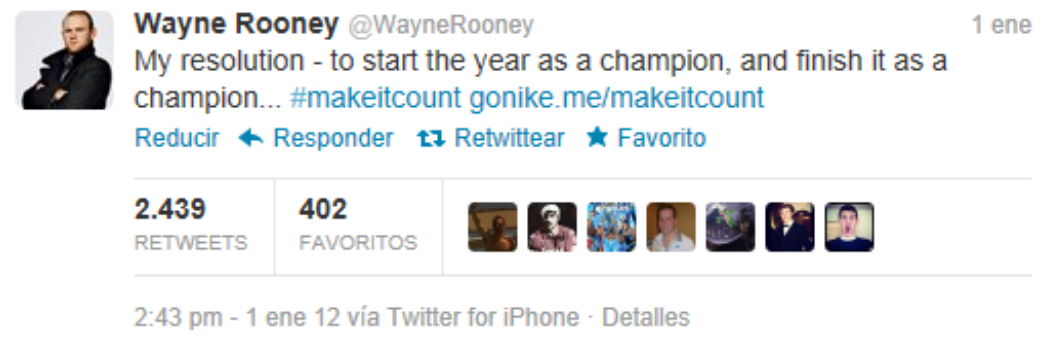

Figura 10. Tuit de Wayne Rooney para la campaña de Nike \#makeitcount En el segundo caso, el ASA dio la razón a Nike frente a la reclamación de un particular contra un tuit de Wayne Rooney que consideraba que dicho mensaje no se identificaba claramente como publicidad, al no incluir la etiqueta \#ad o \#spon. El tuit incluía una mención directa a la cuenta oficial del anunciante, junto a la etiqueta de la campaña (\#myground), además de enlace a una fotografía en la que podía advertirse claramente que se trataba de un anuncio de Nike, por lo que el organismo regulador entendió que el contexto ofrecía suficientes indicios para dejar clara la intencionalidad comercial del mensaje. En consecuencia, el ASA interpretó que el tuit evidenciaba su naturaleza publicitaria sin expresarlo explícitamente. 


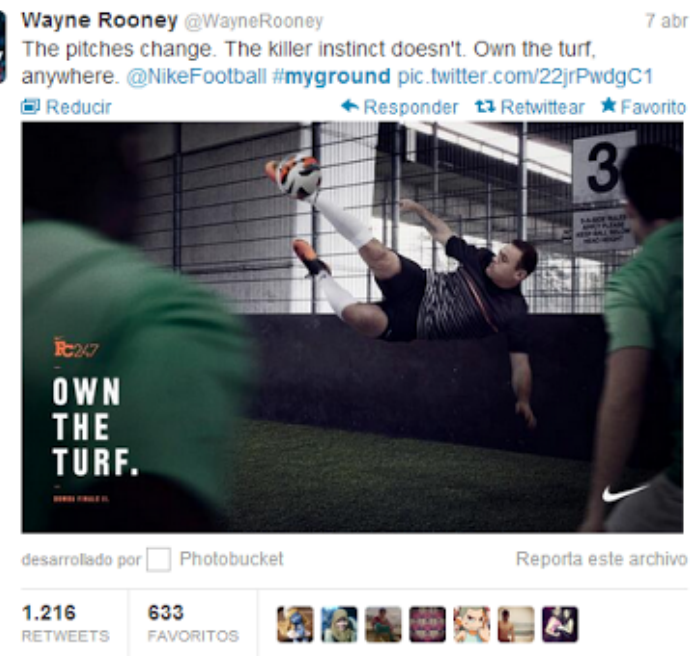

10:53 AM - 7 abr 13 - Detalles

Figura 11. Tuit de Wayne Rooney para campaña de @NikeFootball

En España, uno de los casos más polémicos, que provocó el malestar entre usuarios que tacharon los mensajes de publicidad encubierta por su escasa sutileza y nula credibilidad, es el de Danone. En julio de 2013, varios famosos españoles -Nuria Roca, Carolina Cerezuela, Jesús Vázquez o Santi Millán, entre otros- publicaron en sus perfiles de Twitter un mensaje con la etiqueta \#porfincalor. Lo que parecía ser un simple mensaje personal publicado libre y voluntariamente, ya que no se indicaba que fuera un tuit patrocinado, resultó formar parte de una campaña de Danone para el lanzamiento de su nuevo producto Yolado. Carolina Cerezuela fue la única que integró el hashtag \#publi dentro de su mensaje. 


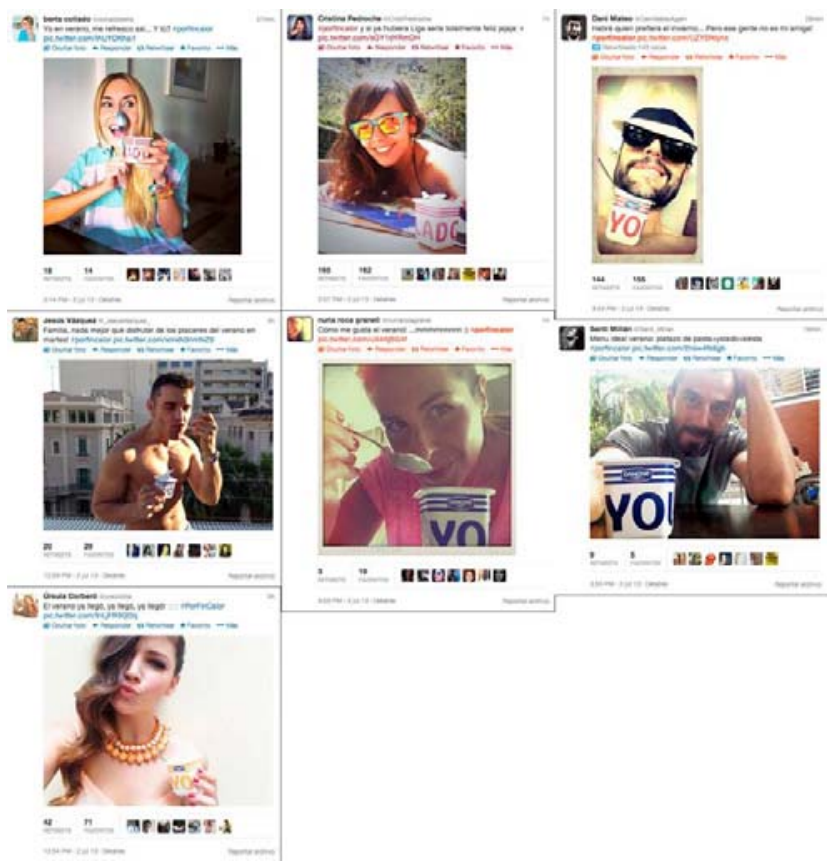

Figura 12. Publicaciones de famosos en Twitter con Yolado de Danone La obligatoriedad de transparencia y autenticidad que la normativa impone a la publicidad en ocasiones choca con los intereses de los anunciantes, que aspiran a integrar su publicidad con naturalidad para incrementar la eficacia de sus inversiones publicitarias y esquivar la saturación publicitaria a la que se enfrenta el usuario en los soportes publicitarios tradicionales. Para otros, a obligatoriedad de identificar los tuits de influencers a propósito de marcas como publicidad es un proteccionismo absurdo e infantil que menosprecia las capacidades del usuario.

Sin embargo, la publicidad ideal ha de ser auténtica, es decir, identificable como tal, y las marcas deben tener presente el marco legal en el que desarrollan sus acciones comunicativas, para evitar daños en su credibilidad e imagen corporativa. Identificar de manera explícita el propósito comercial del mensaje y hacer evidente que se trata de contenido publicitario a través del contexto para no inducir a error al consumidor es lo deseable, también en acciones de marketing de influencia con prescriptores.

\section{CONCLUSIONES}

REDMARKA UIMA-Universidad de A Coruña - CIECID 
A lo largo de estas páginas ha quedado demostrado cómo el poder de recomendación e influencia gracias a las redes sociales ${ }^{18}$ es muy efectivo, y este hecho no ha pasado desapercibido para las marcas y empresas; los nuevos medios han dado a luz a los llamados influenciadores digitales, tuiteros, blogeros 0 youtubers que aunque no sumen tantos seguidores como los famosos tradicionales pueden aportar una mayor segmentación al mensaje de la marca. No hay que olvidar que en el marketing de influencia la colaboración ha de ser win-towin, de manera que las dos partes obtengan beneficio, no sólo económico.

En suma, en un momento de globalización como el que vivimos, cuando resulta poco probable esconder segundas intenciones sin ser descubiertas, todo parece indicar que las empresas deben extremar sus precauciones a la hora de combinar sus intereses publicitarios y de marketing con los propios intereses de los usuarios, especialmente si las redes sociales entran en juego, siempre velando por no traspasar los límites marcados por la legalidad y la ética.

Si una de las bases de las redes sociales es la recomendación, queda por ver cómo evolucionará la publicidad en entornos en los que resulta sencillo mezclar aquellas que se hacen con ánimo de resultar útiles a los seguidores y las que son animadas por un fin lucrativo.

En definitiva, las acciones publicitarias con influenciadores digitales reproducen la figura del tradicional prescriptor en publicidad, pero con particularidades propias de un nuevo marketing, que pone de manifiesto los cambios ante los que nos encontramos, producidos al hilo de la actual revolución tecnológica. Sea como fuere, el diseño de acciones de marketing de influencia debe entenderse como parte de la estrategia de comunicación integral de la marca en una época en la que la publicidad ha de ser transmedia y multidisciplinar.

\section{REFERENCIAS BIBLIOGRÁFICAS}

Agrawal, J. \& Kamakura, W. (1995). THE ECONOMIC WORTH OF CELEBRITY ENDORSERS: AN EVENT STUDY ANALYSIS, Journal of Marketing, n 59, pp 5662. 
Aguado Guadalupe, G. (2015). INBOUND MARKETING EN LINKEDIN PARA LA GESTIÓN DE MARCA, Icono 14, vol. 13, pp. 105-124. doi: http://www.icono14.net/ojs/index.php/icono14/article/view/741. Consultado el 06/03/2015.

Baena Graciá, V. (2011). Fundamentos de marketing: entorno, consumidor, estrategia e investigación comercial. Barcelona: UOC.

Best, R. J. (2007). Marketing estratégico. Madrid: Pearson Educación.

Castelló Martínez, A. (2010). Estrategias empresariales en la Web 2.0. Alicante: ECU.

Celaya, J. (2008). La empresa en la Web 2.0. Madrid: Gestión 2000.

Chiesa de Negri, C. (2005). CRM. Las cinco pirámides del Marketing Relacional. Barcelona: Ediciones Deusto.

Cuesta Fernández, F. (2003). Fidelización... Un paso más allá de la retención. Madrid: McGraw-Hill.

Del Pino, C., Castelló, A. \& Ramos-Soler, I. (2013). La comunicación en cambio constante.

Díez de Castro, E. C. \& Marín Armario, E. (1999). Planificación publicitaria. Madrid: Pirámide.

García Uceda, M. (2001). Las claves de la publicidad. Madrid: ESIC.

García Valdés-Cifuentes, A. \& Fernández Sanz, J. M. (1990). Los anunciantes descubren la tele. Madrid: Cámara del Comercio e Industria de Madrid.

González, J., Salutregui, J. \& Sánchez del Toro, J (2004). Más allá del CRM y el marketing relacional: personalización. Madrid: Prentice Hall.

Jiménez, M., Olarte. C. \& Reinares Lara, E. (2008). Influencia de la publicidad en las tendencias sociales: una aproximación exploratoria al mercado publicitario español. Estableciendo puentes en una economía global. Salamanca: XXII Congreso AEDEM.

Pintado Blanco, T. \& Sánchez Herrera, J. (2012). Nuevas tendencias de comunicación. Madrid: ESIC.

\section{NOTAS}


${ }^{1}$ Según Nielsen, el $92 \%$ de las personas se fían y valoran positivamente las recomendaciones de su entorno directo, realizado a través de un canal no 2.0. Extraído de: http://bit.ly/1FqAyZs. Consultado el 11/03/2015.

${ }^{2}$ Pueden contrastarse: 1. "El fenómeno de las redes sociales. Percepción, usos y publicidad". Disponible en: http://bit.ly/1bc5iCl. Consultado el 11/03/2015. 2. "Estudio sobre uso, interés, conocimiento y percepción de la blogosfera española". Disponible en: http://bit.ly/18T2sAv. Consultado el 11/03/2015.

3 "VI Oleada del Observatorio de Redes Sociales" de The Cocktail Analysis y Arena. Disponible en: https://bitly.com/shorten/. Consultado el 08/03/2015.

${ }^{4}$ Extraído de: http://mun.do/1kB6kXU. Consultado el 18/03/2015.

${ }^{5}$ Disponible en: http://bit.ly/18tGiW7. Consultado el 07/03/2015.

${ }^{6}$ Extraído de: http://bit.ly/1FNpAxC. Consultado el 07/03/2015.

${ }^{7}$ En la tercera temporada de la serie estadounidense Mad Men se analiza el fenómeno, recogido en el documental "Limpiando el Aire: La historia de la publicidad en el tabaco".

${ }^{8}$ Puede verse en: http://bit.ly/1x9TsTb. Consultado el 12/03/2015.

${ }^{9}$ Algo similar le ocurrió a la estrella americana Oprah Winfrey o Alicia Keys, promocionando respectivamente la tableta de Windows MS Surface o el nuevo sistema operativo BB10 de Blackberry desde sus dispositivos Apple; un iPhone en el primer caso y un iPad en el segundo.

${ }^{10}$ Disponible en: http://bit.ly/1x9TsTb. Consultado el 12/03/2015.

${ }^{11}$ Joanna Zaremba sintetiza estas figuras en dos al hilo de la campaña de EcoVidrio protagonizada por Gutiérrez. Se trata de la celebrity y el "influenciador digital", poniendo de manifiesto la versatilidad de esta herramienta de cara a las empresas y especificando el costo que éstas suponen para las compañías, oscilando entre cantidades asumibles -los 50 euros de un personaje anónimo que habla en su blog sobre un producto- a los 20.000 euros por tuit de un personaje famoso del mundo del cine, la televisión o el deporte. Zaremba en: http://bit.ly/1/Lgi9q. Consultado el 07/3/2015.

12 Extraído del blog de Juan Merodio: http://bit.ly/1xHMiAp. Consultado el 07/03/2015. 
${ }^{13}$ Disponible en: http://bit.ly/1FNa6vN. Consultado el 12/03/2015.

${ }^{14}$ Joanna Zaremba en "Marketing de influencia: que tu marca incendie las Redes Sociales": http://bit.ly/1/Lgi9q. Consultado el 18/3/2015.

${ }^{15}$ Disponible en: www.vilmanunez.com. Consultado el 14/03/2015.

${ }^{16}$ Puede consultarse el informe de resultados de la agencia Agents Of Influence en: http://recursos.anuncios.com/files/606/53.pdf. Consultado el 18/03/2015.

${ }^{17}$ Extraído de: http://bit.ly/19325Uc. Consultado el 18/03/2015.

18 Puede verse el documental "Influencers" en: https://vimeo.com/24196514. Consultado el 19/03/2015. 